\title{
Research article \\ Alterations of liver function tests in diabetic obese and nonobese individuals
}

\author{
Avinash S. ${ }^{1}$, Santhi Silambanan ${ }^{2}$ \\ ${ }^{1}$ Postgraduate Student, ${ }^{2}$ Professor, Department of Biochemistry, Sri Ramachandra Institute of Higher Education and Research, \\ Porur, Chennai 600116, Tamil Nadu, India
}

(Received: May $2021 \quad$ Revised: November $2021 \quad$ Accepted: December 2021)

Corresponding author: Santhi Silambanan. Email: santhisilambanan@ sriramachandra.edu.in

\begin{abstract}
Introduction and Aim: India has emerged as the diabetes capital in Southeast Asia having around 74 million with diabetes, with a prevalence of $9.8 \%$ in 18-99 years of age. In type 2 diabetes mellitus, triglycerides get deposited in liver thus altering its structure and function, which is the feature of nonalcoholic fatty liver disease. This study was undertaken to study the alterations in liver function tests in obese and nonobese diabetic individuals.
\end{abstract}

Materials and Methods: The Department of Biochemistry at Sri Ramachandra Institute of Higher Education and Research was chosen to conduct the retrospective study on 200 diabetic individuals from September 2019 to February 2020. The data obtained were serum liver function tests, HbA1c, plasma glucose and lipid profile. Before the study ethics approval was obtained from the Institutional Ethics Committee for studies involving human participants. The obtained data were subjected to statistical analysis using SPSS version 16 and a P value less than 0.05 was considered statistically significant.

Results: Transaminases and ALP were significantly altered in obese diabetics; were positively correlated with bilirubin. TGL was negatively correlated with AST/ALT ratio.

Conclusion: Liver enzymes and bilirubin were altered in obese diabetics. Measurement of liver function biomarkers are cost effective diagnostic markers of non-alcoholic fatty liver disease.

Keywords: Obesity; diabetes mellitus; non-alcoholic steatohepatitis; non-alcoholic fatty liver disease; liver function tests.

\section{INTRODUCTION}

$\mathrm{D}$ iabetes mellitus is a major communicable disease affecting majority of adults of both across the globe. Studies have shown that in 2017451 million were diabetics; by mathematical modeling expected to involve 693 million individuals by 2045 . In India the premature mortality in the age group of 20 to 79 years is $50.7 \%$. The prevalence as per the study by the Indian Council of Medical Research- India Diabetics 2015 involving 15 states in India was 7.3 percentage (1). In patients with type 2 diabetes mellitus (T2DM) there is increased glucagon activity in comparison to insulin activity. This results in uncontrolled lipolysis with excessive amount of free fatty acids reaching the first pass that is the liver. The liver converts the fatty acids to condensation compound that is triglyceride (TGL) and transports them out of liver as very low-density lipoprotein (VLDL). But the amount the free fatty acids is beyond the capacity of liver to convert them to VLDL, hence they get accumulated in liver leading to nonalcoholic fatty liver disease (NAFLD). Diabetic individuals are predisposed to low grade inflammation which also enhances inflammation of the liver resulting in altered liver function and liver functions biomarkers (2). NAFLD occurs in the absence of excessive alcohol consumption. In adults it is one of the most common chronic liver diseases across the globe, and its prevalence varies from 10 to $40 \%$, depending on the age, lifestyle, and race/ethnicity. There is substantial evidence that NAFLD is associated with impaired glucose tolerance, T2DM and metabolic syndrome (MetS; 3).

T2DM is associated with obesity irrespective of the economic status. For adults, current guidelines from the US Centers for Disease Control and Prevention (CDC) and the WHO define a normal body mass index (BMI) range is 18.5 to $24.9 \mathrm{~kg} / \mathrm{m}^{2}$, whereas a $\mathrm{BMI} \geq 25$ $\mathrm{kg} / \mathrm{m}^{2}$ is overweight, and a BMI $\geq 30 \mathrm{~kg} / \mathrm{m}^{2}$ is obese. There is an emerging concern in the health care sector is that there is an increasing trend in the prevalence of obesity not only in the developed countries but also in the developing countries. Various reasons have been attributed to this, rapid change in lifestyle such as adopting urban culture, in the form of food and exercise patterns (3). Asia-Pacific guidelines show a lower cutoff for obesity compared to WHO guidelines; underweight is BMI $<18.5 \mathrm{~kg} / \mathrm{m}^{2}$, normal weight with BMI of $18.5-22.9 \mathrm{~kg} / \mathrm{m}^{2}$, overweight with BMI of $23-$ $24.9 \mathrm{~kg} / \mathrm{m}^{2}$, and obese with BMI of $\geq 25 \mathrm{~kg} / \mathrm{m}^{2}(4)$.

Studies show that T2DM induces impairment of liver function (5). MRI has been used for quantifying liver fat but may not be cost effective or may not be accessible for all patients. This study was undertaken to study the alterations in liver function tests which could indicate presence of NAFLD in diabetic obese patients. 


\section{MATERIALS AND METHODS}

The retrospective study was conducted in 200 individuals by obtaining patient data either manually or electronic data sheets at Medical Records Department, Sri Ramachandra Institute of Higher Education and Research, Porur, Chennai during the period from September 2019 to February 2020. Inclusion criteria were 40 to 70 years of age of both genders, fasting plasma glucose $>126 \mathrm{mg} / \mathrm{dL}$ and/or postprandial plasma glucose $>200 \mathrm{mg} / \mathrm{dL}$ and $\mathrm{HbA}_{1 \mathrm{C}}>5.7 \%$. Exclusion criteria were patients with history of clinically significant cardiovascular, respiratory, liver, renal and autoimmune disorders, hepatitis B and HIV infections, use of drugs such as corticosteroids, griseofulvin, sodium valproate, amiodarone, anticancer drugs-tamoxifen, cisplatin and methotrexate; and pregnant women.

Study participants were classified into three groups: Group I ( $\mathrm{n}=37)$ were normal weight diabetics with BMI of $18.5-22.9 \mathrm{~kg} / \mathrm{m}^{2}$, Group II $(\mathrm{n}=71)$ were overweight diabetics with BMI of $23-24.9 \mathrm{~kg} / \mathrm{m}^{2}$, and Group III ( $\mathrm{n}=92)$ were obese diabetics with BMI of $\geq 25 \mathrm{~kg} / \mathrm{m}^{2}$. Patient records were searched for data with regard to liver function tests, glycemic status markers such as fasting plasma glucose, postprandial plasma glucose and glycated hemoglobin, lipid and renal profiles. The Institutional Ethics Committee approval was obtained (CSP/20/NOV/87/180, dated 30-112020). Informed consent could not be obtained as the study was a retrospective study and the patients were treated and discharged from the hospital. Statistical analysis was performed using SPSS version 16.0. Data were subjected to Kolmogorov-Smirnov test. Depending on the presence or absence of normality of distribution, results were expressed either as mean \pm SD or median and interquartile range. ANOVA and Kruskal Wallis tests were applied for comparison. Spearman correlation was done. $\mathrm{P}$ value $<0.05$ was considered significant.

\section{RESULTS}

In the present study, comprising of 200 patients, 119 (59.5\%) were males and $81(40.5 \%)$ were females.

A comparison of fasting and postprandial plasma glucose levels in groups I, II and III were not statistically significant $(\mathrm{P}=0.429)$ and $(\mathrm{P}=0.179)$ respectively. Also, there was no statistical significance in HbA1c $(\mathrm{P}=0.055)$. Kidney functions were preserved as shown by blood urea nitrogen and creatinine remaining within the biological reference interval even in the stage of obesity (Table 1).

Table 1: Comparison of biochemical parameters between the three study groups

\begin{tabular}{|c|c|c|c|c|}
\hline Parameters & $\begin{array}{l}\text { Group I Normal } \\
(\mathrm{n}=37)\end{array}$ & $\begin{array}{l}\text { Group II Overweight } \\
(\mathrm{n}=71)\end{array}$ & $\begin{array}{l}\text { Group III Obese } \\
(\mathrm{n}=92)\end{array}$ & $\begin{array}{c}\mathrm{P} \\
\text { Value }\end{array}$ \\
\hline Fasting plasma glucose mg/dL (Mean \pm SD) & $187 \pm 80.71$ & $169 \pm 57.06$ & $175.65 \pm 64.55$ & 0.429 \\
\hline Postprandial plasma glucose mg/dL (Mean \pm SD) & $273 \pm 108.20$ & $267.3 \pm 87.12$ & $245.99 \pm 85.34$ & 0.179 \\
\hline $\mathrm{HbA}_{1 \mathrm{C}} \%($ Mean $\pm \mathrm{SD})$ & $8.94 \pm 2.81$ & $9.35 \pm 3.00$ & $8.38 \pm 2.00$ & 0.055 \\
\hline BUN mg/dL (Mean \pm SD) & $14.95 \pm 10.72$ & $18.69 \pm 15.03$ & $14.88 \pm 9.76$ & 0.107 \\
\hline Creatinine mg/dL [Median, (IQR)] & $0.80(0.60,1.10)$ & $0.90(0.70,1.30)$ & $0.8(0.60,1.17)$ & 0.306 \\
\hline Total cholesterol mg/dL (Mean \pm SD) & $166.14 \pm 57.42$ & $169.13 \pm 49.23$ & $163.46 \pm 50.01$ & 0.785 \\
\hline TGL mg/dL [Median, (IQR)] & $125(94,208)$ & $126.50(92.75,177.50)$ & $138(107,196)$ & 0.592 \\
\hline HDL mg/dL (Mean \pm SD) & $36.76 \pm 10.73$ & $36.63 \pm 11.84$ & $36.15 \pm 11.96$ & 0.951 \\
\hline LDL mg/dL (Mean \pm SD) & $105.24 \pm 37.53$ & $110.77 \pm 35.71$ & $104.67 \pm 34.89$ & 0.533 \\
\hline
\end{tabular}

Parameter expressed in mean \pm SD was compared using ANOVA; median and IQR were compared using Kruskal-Wallis Test.

There was no statistical difference in fasting and postprandial plasma glucose values and HbA1c between the three study groups. It showed that there was no difference in diabetic status across the groups which had allowed for comparisons of other parameters between the groups. There were no statistically significant differences in renal function parameters as well as lipid profile between the groups.

In the present study, total protein and albumin when compared between the three groups were not statistically significant $(\mathrm{P}=0.777)$ and $(\mathrm{P}=0.866)$ respectively. The median and interquartile range of aspartate transaminase (AST) in groups I, II, and III were $23 \mathrm{U} / \mathrm{L}(16,40), 31 \mathrm{U} / \mathrm{L}(21,52)$ and $22(17,34.5)$ $\mathrm{U} / \mathrm{L}$ respectively which was statistically significant $(\mathrm{P}=0.008)$ (Table 2). There was statistically significant difference when groups II and III $(\mathrm{P}=0.002)$ were compared and between groups I and II $(\mathrm{P}=0.042$; Table 3). The median and interquartile range in alanine transaminase (ALT) in groups I, II and III were 18U/L (13,29), 27U/L (17,54) and 18U/L (13,28.75) $\mathrm{U} / \mathrm{L}$ respectively which was statistically significant $(\mathrm{P}=0.003)$ (Table 2). There was statistically significant difference between groups II and III $(\mathrm{P}=0.001)$ and between groups I and II ( $\mathrm{P}=0.016)$. (Table 3) But AST/ALT ratio was not significant across the groups $(\mathrm{P}=0.507)$.

There was statistically significant difference in alkaline phosphatase (ALP) in groups I, II and III with levels $88 \mathrm{U} / \mathrm{L}(67.50,126.50), 105 \mathrm{U} / \mathrm{L}(80,132)$ and $87 \mathrm{U} / \mathrm{L}(73.25,107.75) \mathrm{U} / \mathrm{L}$ respectively $(\mathrm{P}=0.026)$ (Table 2). Posthoc analysis of ALP showed that there was statistically significant difference when groups II were compared against III ( $\mathrm{P}=0.008)$ (Table 3$)$. Thus, it was shown that as BMI increased there were alterations in liver enzymes. There were significant increases in AST, ALT and ALP between the 
overweight and obese groups with higher values in the overweight group. This could be due to improved diabetic status in the obese group compared to overweight group. There were no statistically significant differences between the groups I, II and III in total bilirubin $(\mathrm{P}=0.54)$ and direct bilirubin $(\mathrm{P}=0.472)$. (Table 2) Barakat et al., have shown almost the same levels of AST and ALT (16).

Table 2: Comparison of liver function parameter between the three study groups

\begin{tabular}{|c|c|c|c|c|}
\hline Parameters & $\begin{array}{c}\text { Group I Normal } \\
(\mathrm{n}=37)\end{array}$ & $\begin{array}{c}\text { Group II } \\
\text { Overweight }(\mathrm{n}=71)\end{array}$ & $\begin{array}{c}\text { Group III Obese } \\
(\mathrm{n}=92)\end{array}$ & P Value \\
\hline Total protein g/dL (Mean \pm SD) & $6.67 \pm 0.88$ & $6.79 \pm 0.78$ & $6.74 \pm 0.78$ & 0.777 \\
\hline Albumin g/dL (Mean \pm SD) & $3.50 \pm 0.60$ & $3.58 \pm 0.66$ & $3.50 \pm 0.68$ & 0.866 \\
\hline AST U/L [Median, (IQR)] & $23(16,40)$ & $31(21,52)$ & $22(17,34.5)$ & $0.008^{* *}$ \\
\hline ALT U/L [Median, (IQR)] & $18(13,29)$ & $27(17,54)$ & $18(13,28.75)$ & $0.003 * *$ \\
\hline AST/ALT ratio [Median, (IQR)] & $1.31(1.06,1.60)$ & $1.14(0.86,1.67)$ & $1.20(1.0,1.69)$ & 0.507 \\
\hline ALP U/L [Median, (IQR)] & $88(67.50,126.50)$ & $105(80,132)$ & $87(73.25,107.75)$ & $0.026^{*}$ \\
\hline Total bilirubin mg/dL [Median, (IQR)] & $0.60(0.39,0.78)$ & $0.62(0.45,0.92)$ & $0.62(0.43,0.92)$ & 0.540 \\
\hline Direct bilirubin mg/dL [Median, (IQR)] & $0.12(0.09,0.16)$ & $0.13(0.09,0.21)$ & $0.13(0.09,0.21)$ & 0.472 \\
\hline
\end{tabular}

Parameters expressed in mean \pm SD were compared using ANOVA and parameters expressed in median, IQR were compared using Kruskal-Wallis test.

*P value: significant; ** $\mathrm{P}$ value: highly significant.

When liver function tests were compared between the variables the enzymes- AST, ALT and ALP showed statistically significant differences between the three groups.

Table 3: Comparison of liver function parameters between the three study groups using Tukey Posthoc analysis

\begin{tabular}{|c|c|c|c|}
\hline & \multicolumn{3}{|c|}{ P Value } \\
\hline Parameters & Groups I vs II & Groups II vs III & Groups I vs III \\
\hline AST U/L & $0.042^{*}$ & $0.002^{* *}$ & 0.907 \\
\hline ALT U/L & $0.016^{*}$ & $0.001^{* *}$ & 0.950 \\
\hline ALP U/L & 0.082 & $0.008^{* *}$ & 0.901 \\
\hline
\end{tabular}

*P value: significant; $* * \mathrm{P}$ value: highly significant

When posthoc was done to find out the statistically significant difference in liver enzymes between the groups, statistically significant differences were obtained in transaminase between normal and overweight groups as well as between overweight and

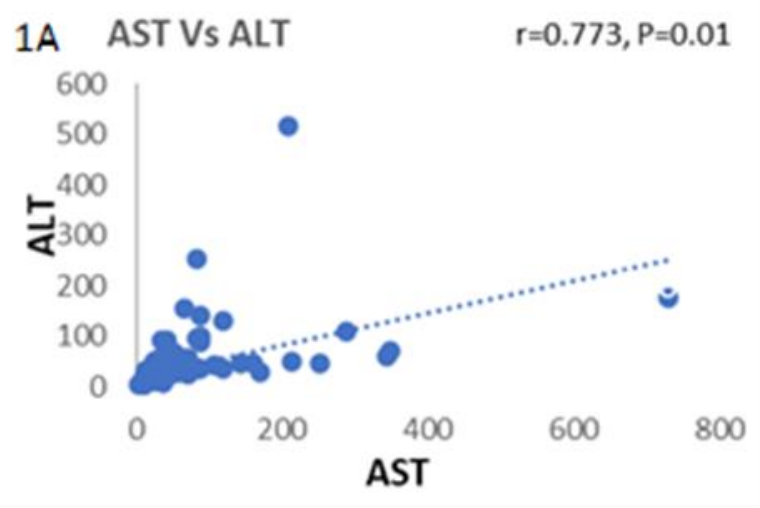

$1 C$ AST Vs Direct bilirubin $\quad r=0.329, P=0.01$

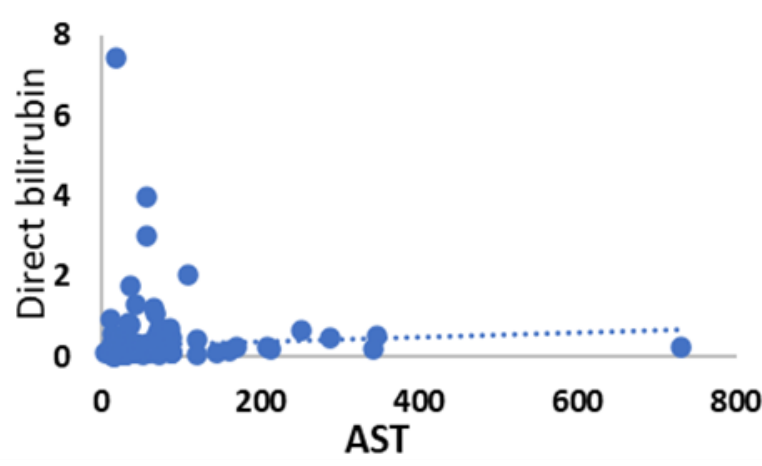

obese groups. ALP showed statistically significant difference between only between overweight and obese individuals but there was no statistically significant difference between normal and overweight individuals.
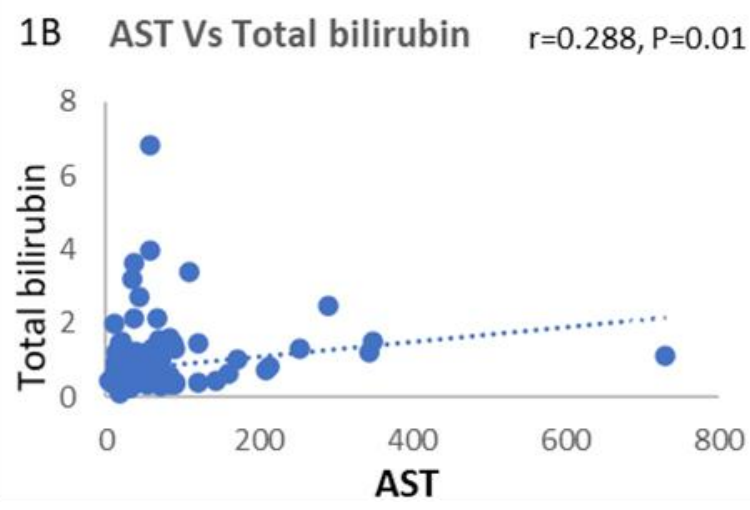

$1 D$ ALT Vs Total bilirubin $r=0.255, P=0.01$

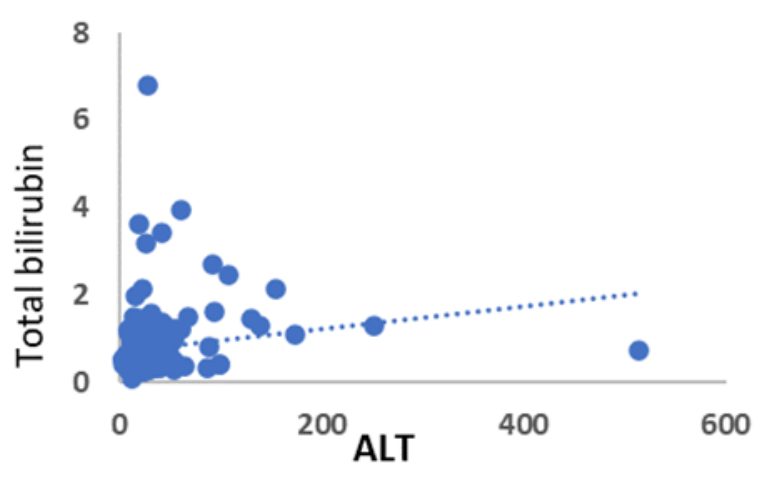



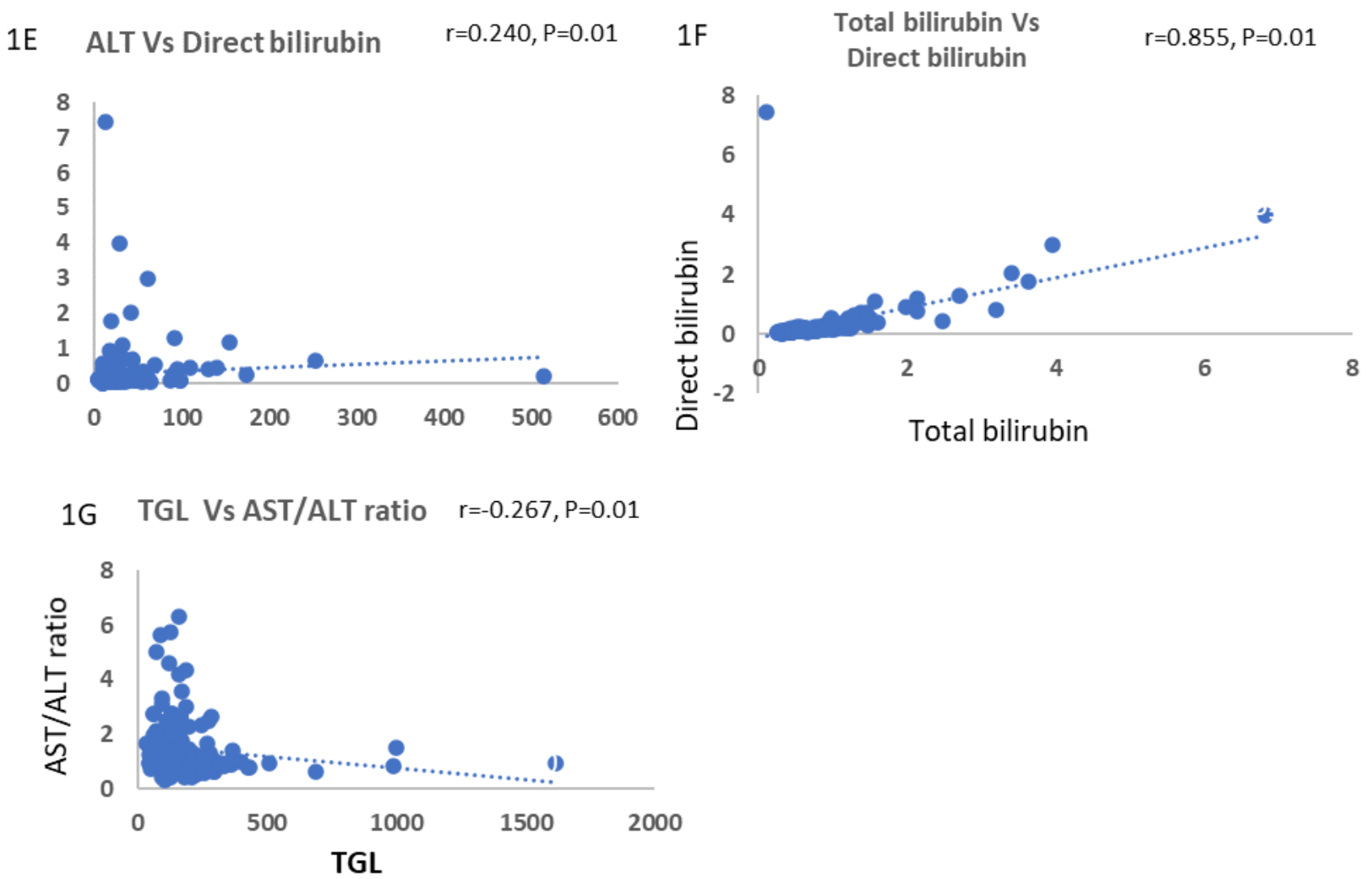

Fig. 1: Spearman correlation of liver function parameters and biochemical parameters.

There was positive correlation between AST and ALT. There were positive correlations when ALT and AST were compared with total and direct bilirubin. Also, there was a positive correlation between total and direct bilirubin. There was negative correlation when TGL was compared with AST/ALT ratio. All the comparisons showed statistically significant differences.

Table 4: Obesity classification according to WHO and Asia-Pacific guidelines

\begin{tabular}{|c|c|c|}
\hline & WHO (BMI) & Asia-Pacific (BMI) \\
\hline Underweight $\left(\mathrm{kg} / \mathrm{m}^{2}\right)$ & $<18.5$ & $<18.5$ \\
\hline Normal $\left(\mathrm{kg} / \mathrm{m}^{2}\right)$ & $18.5-24.9$ & $18.5-22.9$ \\
\hline Overweight $\left(\mathrm{kg} / \mathrm{m}^{2}\right)$ & $25-29.9$ & $23-24.9$ \\
\hline Obese $\left(\mathrm{kg} / \mathrm{m}^{2}\right)$ & $\geq 30$ & $\geq 25$ \\
\hline
\end{tabular}

A study was conducted by National Health Survey in most states of India to show the distribution of obesity among men and women between the age group 15 and 49 years old. (Fig. 2; 7)

\begin{tabular}{|c|c|c|c|c|}
\hline \multicolumn{5}{|c|}{ Percentage of obesity among men and women (15-49 years old) } \\
\hline & Men - NFHS 4 & NHFS - 3 & Women - NHFS 4 & NHFS - 3 \\
\hline Bihar - & -12.6 & 4.6 & $\square 11.7$ & 4.6 \\
\hline Goa - & 32.6 & 20.2 & 33.5 & 20.2 \\
\hline Haryana - & $\square 20$ & 17.4 & 乙21 & 17.4 \\
\hline Karnataka - & 22.1 & 15.3 & 23.3 & 15.3 \\
\hline MP - & 10.9 & 7.6 & 13.6 & 7.6 \\
\hline Meghalaya - & 10.1 & 5.3 & 12.2 & 5.3 \\
\hline $\mathrm{TN}-$ & 28.2 & 20.9 & 30.9 & 20.9 \\
\hline WB - & $\square 14.2$ & $\square 11.4$ & $\square 19.9$ & 11.4 \\
\hline
\end{tabular}

Fig. 2: Depicting the percentage of obesity among men and women (15-49 years old)

In the present study, AST was positively correlated with ALT ( $\mathrm{r}=0.773 ; \mathrm{P}=0.01$ ) (Fig. 1A). The minimal increase in AST in the overweight group was seen with ALT also. Sanyal et al., found a positive correlation between AST and ALT (17). AST was positively correlated with total and direct bilirubin 
$(\mathrm{r}=0.288 ; \mathrm{P}=0.01)$ (Fig. 1B) and $(\mathrm{r}=0.329 ; \mathrm{P}=0.01)$ (Fig. 1C). ALT was positively correlated with total and direct bilirubin $(\mathrm{r}=0.255 ; \mathrm{P}=0.01)$ (Fig. 1D) and $(\mathrm{r}=0.240 ; \quad \mathrm{P}=0.01) \quad$ (Fig. 1E) respectively. Total bilirubin was positively correlated with direct bilirubin ( $\mathrm{r}=0.855 ; \mathrm{P}=0.01$ ) (Fig. 1F). TGL were negatively correlated with AST/ALT ratio $(\mathrm{r}=-0.267$; $\mathrm{P}=0.01$ ) (Fig. 1G).

\section{DISCUSSION}

Type 2 diabetes mellitus (T2DM) is found to be associated with obesity. T2DM is found to have endothelial dysfunction and insulin resistance (3). A study by Bandaru et al., has shown that obesity was present in $59.2 \%$ of patients with NAFLD. The prevalence of obesity has shown to vary widely from $22 \%$ to as high as $74 \%$ in studies involving children as well as adults. Men seem to show a higher prevalence of obesity with prevalence of $50.5 \%$ while women showed lesser prevalence of $38.9 \%$; obesity was associated with NAFLD (6). The increase in prevalence of obesity irrespective of age. In adults, the increasing trend is being associated with increasing individuals affected by diabetes mellitus, hypertension, coronary artery disease (CAD), NAFLD, certain cancer, obstructive sleep apnea and sudden death (3).

Obesity is defined as excessive accumulation of fat that is triglycerides in the adipose tissue. The World Health Organization (WHO) has categorized obesity based on body mass index (BMI). The first possible explanation that DM induces liver function abnormality is the deposition of fat in the liver which is the characteristic feature of NAFLD. According to Asia-Pacific guidelines, the individuals are classified based on BMI as $18.5 \mathrm{~kg} / \mathrm{m}^{2}$ being underweight, 18.5 $22.9 \mathrm{~kg} / \mathrm{m}^{2}$ is normal, $23-24.9 \mathrm{~kg} / \mathrm{m}^{2}$ is overweight and greater than or equal to $25 \mathrm{~kg} / \mathrm{m}^{2}$ is obese (4).

The present study was conducted in 200 T2DM patients of which, $119(59.50 \%)$ males, and 81(40.50) females. The study population were divided into three groups of T2DM patients, according to their BMI; group I with normal BMI of $18.5-22.9 \mathrm{~kg} / \mathrm{m}^{2}$ present in $25(65.80 \%)$ males and $13(34.20 \%)$ females, group II with BMI of $23-24.9 \mathrm{~kg} / \mathrm{m}^{2}$ present in $42(61.80 \%)$ males and 26(38.20\%) females, and group III with BMI of $\geq 25 \mathrm{~kg} / \mathrm{m}^{2}$ present in $50(55 \%)$ males and $41(45 \%)$ females. Majority of the study participants were males. Studies have mentioned that around 30$40 \%$ of obesity have genetic component whereas the rest $60-70 \%$ is due to environmental factors. Usually there is an interplay by both the components (8).

In the present study it was found that in groups I, II and III there were $2.60 \%, 5.90 \%$ and $0 \%$ were alcoholics respectively. Even those alcoholics were only social and not habitual drinkers. Hypertension was present in $52.60 \%, 67.60 \%$ and $60 \%$ in groups I, II and III respectively. When enquired about the type of diet consumed, in group I, 78.90\% were on diabetic and salt restricted diet, $15.80 \%$ were on mixed diet and $5.30 \%$ were on normal diet; in group II $75 \%$ were on diabetic and salt restricted diet, $19.10 \%$ were on mixed diet and $5.90 \%$ were on normal diet, and in group III $84.62 \%$ were on diabetic and salt restricted diet, $12.09 \%$ were on mixed diet and $3.29 \%$ were on normal diet. Pathogenesis behind the presence of hypertension associated with obesity is that there is activation of sympathetic nervous system and rennin angiotensin aldosterone system (9).

Obese individuals require several folds higher insulin levels than non-obese individuals to maintain normal glucose tolerance (10). Obesity is associated with post-receptor binding defects in insulin action, including impaired generation of second messengers, diminished glucose transport, and abnormalities in glucose utilization (10).

In the present study, there was no alteration of total cholesterol in all the diabetic study groups (Table 1). But there was decreased HDL and increased LDL in all the study groups, but there were no significant differences between the groups. The absence of statistically significant differences in lipid profile could be due to small sample size. Increased FFAs increase VLDL production by the liver, reducing high density lipoprotein (HDL)-cholesterol levels, and increasing the number of small dense low-density lipoprotein (LDL) particles (3). In obesity, depending on the extent of TGL accumulation and its effect on liver structure and function, there are varied liver disorders. In few cases NAFLD could be associated with inflammation and fibrosis of hepatocytes, the condition called steatohepatitis. In the long run it leads to cirrhosis. NAFLD is associated metabolic syndrome (MetS) (3). NAFLD is associated with coronary artery disease as shown by decreased myocardial perfusion, left ventricular dysfunction and increased carotid intima-media thickness. (11) Also, NAFLD is associated with occurrence of microvascular complications of T2DM (12). Liver biopsy is regarded as the gold standard for the assessment of NAFLD. But it is invasive; is therefore, unsuitable for screening large numbers of individuals at risk (12). Various radiological methods are being used to quantify the TGL deposited in the liver (13). The extent of TGL deposition in liver is graded as I, II and III by ultrasonography (14).

Abnormal liver enzyme levels may signal liver damage or alterations in bile flow (15). Isolated alterations of liver biochemical markers in a healthy patient represents poses a challenge to the clinician (5).

A study by Tian et al., has found that total and direct bilirubin values were inversely proportional to the stage of NAFLD; the decrease was attributed to antioxidant role of bilirubin (18). In the present study, 
increase of direct bilirubin and ALP indicate that there could be intrahepatic obstruction due to TGL accumulation in liver causing physical obstruction or it can be due to fibrosis resulting from fatty liver. Since in NAFLD, there are alterations in liver enzymes; National Health and Nutritional Survey has found that 23\% adults have NAFLD (19). Studies show alterations in transaminases and gamma glutamyl transferase (20). AST/ALT ratio greater than 1 is highly suggestive of advanced liver disease (21). Various communicable and noncommunicable disorders result in fatty liver in addition to alcoholand drug- abuse. Hence diagnosis of NAFLD of obesity and T2DM origin is merely by exclusion of other causes of fatty liver (22).

\section{Limitation of the study}

To study the alteration of liver function tests in diabetic obese and nonobese individuals as a prospective cohort study is desirable. Sample size of the study was small to obtain correlation between LFT and dyslipidaemia and to include features of fatty liver obtained by MRI and also to include glycated albumin and advanced glycation end products (AGE).

\section{CONCLUSION}

Serum AST, ALT and ALP were statistically significant in the obese diabetic groups. Both serum AST and ALT were positively correlated with total and direct bilirubin. Serum total and direct bilirubin were positively correlated. TGL was negatively correlated with AST/ALT ratio. Total protein, serum albumin, total protein and direct bilirubin were within biological reference intervals.

\section{ACKNOWLEDGEMENT}

The authors wish to acknowledge the institution for providing patient details and necessary infrastructure for conducting the study. The authors wish to thank the patients whose data were included in the study.

\section{CONFLICT OF INTEREST}

The authors wish to express that there was no conflict of interest while conducting the study as well as during the publication of this research work.

\section{REFERENCES}

1. Borgharkar, S. S., Das, S. S. Real-world evidence of glycemic control among patients with type 2 diabetes mellitus in India: the TIGHT study. BMJ Open Diabetes Res Care. 2019 Jul 14;7(1): e000654.

2. Sanjeevaiah, A., Sushmitha, A., Srikanth, T. Prevalence of Diabetes Mellitus and its risk factors. IAIM. 2019; 6(3): 319324.

3. Manson, J. E., Willett, W. C., Stampfer, M. J., Colditz, G. A., Hunter, D. J., Hankinson, S. E., et al., Body weight and mortality among women. N Engl J Med. 1995; 333(11): 677685.

4. Lim, J. U., Lee, J. H., Kim, J. S., Hwang, Y. I., Kim, T. H., Lim, S. Y., et al., Comparison of World Health Organization and Asia-Pacific body mass index classifications in COPD patients. International journal of chronic obstructive pulmonary disease. $2017 ; 12: 2465-2475$.
5. Kotronen, A., Peltonen, M., Hakkarainen, A., Sevastianova, K., Bergholm, R., Johansson, L.M., et al., Prediction of nonalcoholic fatty liver disease and liver fat using metabolic and genetic factors. Gastroenterology. 2009; 137(3): 865-872.

6. Bandaru, V. S., Chaudhury, J. R., Lalitha, P., Reddy, S. N., Misra, P. K., Balaraju, B., et al., Prevalence of asymptomatic nonalcoholic fatty liver disease in nondiabetic participants: a study from South India. The Egyptian Journal of Internal Medicine. 2019; 31(1): 92-98.

7. Shams, M. E., Al-Gayyar, M. M., Barakat, E. A. Type 2 diabetes mellitus-induced hyperglycemia in patients with NAFLD and normal LFTs: relationship to lipid profile, oxidative stress and pro-inflammatory cytokines. Scientia pharmaceutica. 2011; 79(3): 623-634.

8. Stunkard, A. J. The Salmon lecture. Some perspectives on human obesity: its causes. Bull NY Acad Med. 1988; 64: 902923.

9. Jiang, S. Z., Lu, W., Zong, X. F., Ruan, H. Y., Liu, Y. Obesity and hypertension. Experimental and therapeutic medicine. 2016; 12(4): 2395-2399.

10. Caro, J. F., Dohm, L. G., Pories, W. J., Sinha, M. K. Cellular alterations in liver and skeletal muscle, and adipose tissue responsible for insulin resistance in obesity and type II diabetes. Diabetes Metab Rev 1989; 5: 665-689.

11. Dharmalingam, M., Yamasandhi, P. G. Nonalcoholic Fatty Liver Disease and Type 2 Diabetes Mellitus. Indian J Endocrinol Metab. 2018; 22(3): 421-428.

12. Targher, G., Bertolini, L., Rodella, S., Tessari, R., Zenari, L., Lippi, G., et al., Nonalcoholic fatty liver disease is independently associated with an increased incidence of cardiovascular events in type 2 diabetic patients. Diabetes Care. 2007; 30(8): 2119-2121.

13. Ix, J. H., Sharma, K. Review Mechanisms linking obesity, chronic kidney disease, and fatty liver disease: the roles of fetuin-A, adiponectin, and AMPK. J Am Soc Nephrol. 2010; 21(3): 406-412.

14. Hernaez, R., Lazo, M., Bonekamp, S., Kamel, I., Brancati, F.L., Guallar, E., et al., Diagnostic accuracy and reliability of ultrasonography for the detection of fatty liver: a metaanalysis. Hepatology 2011;54(3):1082-1090.

15. EASL-EASD-EASO Clinical Practice Guidelines for the management of non-alcoholic fatty liver disease. J Hepatol. 2016 Jun; 64(6): 1388-402. doi: 10.1016/j.jhep.2015.11.004.

16. Ronnemaa, T., Koskenvuo, M., Marniemi, J., Koivunen, T., Sajantila, A., Rissanen, A., et al., Glucose metabolism in identical twins discordant for obesity. The critical role of visceral fat. J Clin Endocrinol Metab. 1997; 82: 383-387.

17. Sanyal, D., Mukherjee, P., Raychaudhuri, M., Ghosh, S., Mukherjee, S., Chowdhury, S. Profile of liver enzymes in non-alcoholic fatty liver disease in patients with impaired glucose tolerance and newly detected untreated type 2 diabetes. Indian journal of endocrinology and metabolism. 2015; 19(5): 597-601.

18. Tian, J., Zhong, R., Liu, C., Tang, Y., Gong, J., Chang, J., et al., Association between bilirubin and risk of Non-Alcoholic Fatty Liver Disease based on a prospective cohort study. Sci Rep. 2016; 6: 31006.

19. Burkitt, H. G., Young, B., Heath, J. W., Wheater, P. R. Wheater's functional histology: A text and colour atlas. Edinburgh: Churchill Livingstone. 1993. Print.

20. Worobetz, L., Hilsden, R., Shaffer, E., Simon, J., Pare, P., Scully, L., et al., The liver. In Thomson BR, Shaffer EA, editors. First Principles of Gastroenterology. $2^{\text {nd }}$ ed. University of Toronto Press: Toronto; 1994.

21. Harrison, S. A., Kadakia, S., Lang, K. A., Schenker, S. Nonalcoholic steatohepatitis: what we know in the new millennium. Am J Gastroenterol. 2002; 97(11): 2714-2724.

22. Brunt, E.M. Non-alcoholic steatohepatitis. Semin Liver Dis 2004; 24(1): 3-20. 